BOOKS

\title{
Finely crafted, rewarding poems from a Northern doctor
}

\section{Sumac's Red Arms \\ Karen Shklanka \\ Coteau Books; 2009.}

$\mathrm{T}$ his fine collection of poems opens with a series set in Moose Factory, Ontario, where Karen Shklanka practised family and emergency medicine. Working as a doctor in the North is one of the tougher assignments. Added to the isolation, the bitter cold and the long winter, are the almost constant emergencies that afflict native communities: James wakes "bleeding on a battlefield of empties" and walks to the hospital with a deep head wound; Matthew calls to tell her he has been "sitting all morning with a gun to his head; the girl from Attawapiskat is the fifth acetaminophen overdose sent from that village in six weeks. It turns out the bored teens just want to get choppered down so they can go shopping at the Northern store when they are feeling better.

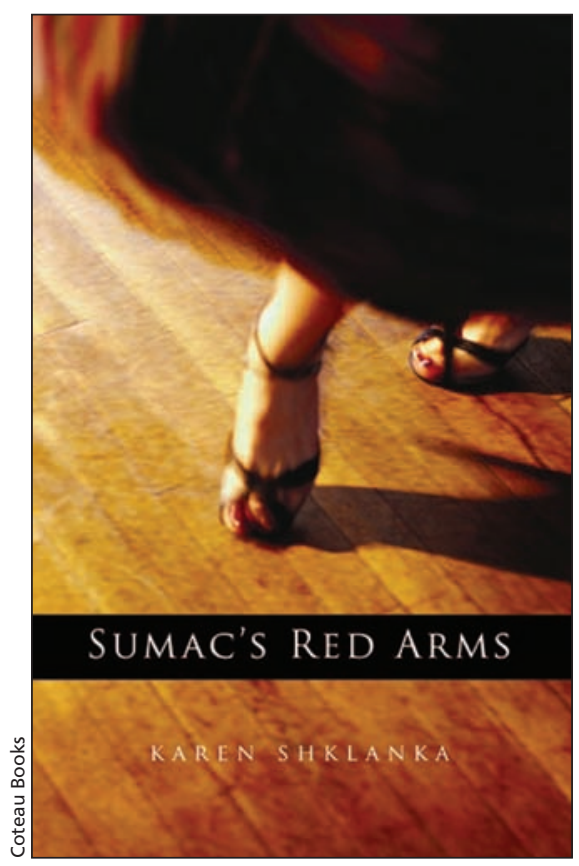

As well as being a doctor, Shklanka is a traveller and a dancer. References to the tango swirl throughout the book, and one section, Vocabulary: A Tango,

\section{These poems provide a powerful, heartbreaking view of lives in distress.}

While these Northern poems constitute less than a quarter of the collection, they are a powerful, heartbreaking view of lives in distress. They also stand as a reminder of what little frustrated medical professionals can do, ultimately, to change these long-term situations. titles fifteen short poems with Spanish words that describe movements of the Argentine tango. Like the dance itself, these swirling elusive poems are dense, rich and erotic. In parada, she writes: "she stops him / slides her toe up / and down / his leg, / what I want: / this, / and this." These poems, in their brevity, quick shifts and sheer physicality, replicate the way two tango dancers relate to the space between them and their own (and each other's) spinning bodies.

The poet's travel poems, included in a section entitled The Scent of Cloves, touch on such diverse locations as Egypt, Africa, Mexico, Barcelona, Seville and Paris. Shklanka turns these places into feasts of colour and fragrance: "secrets from the mussel's orange tongue," "pinwheels of papaya, watermelon, mango," "marmalade on poached pears with red wine, a culinary tango." It seems as if the entire collection includes brilliant highlights thrown off by a tango dancer.

But the serious, down-to-earth life of a physician is never far in the background. In Dear God, she relates: "I want to believe you'll get this letter. / It's been on and off between us. / You show up in snowflakes, eyelashes, blackberry pie, / a newborn warm in my hands." But then, an old professor she admired collapses and dies in front of her. It makes her question things, to wonder. She still wants "to go into the lives of the people," but would prefer to do it now "without sadness and without hope."

This is an excellent collection of finely crafted and rewarding poems.

\author{
Mark Frutkin \\ Poet and author \\ Ottawa, Ont.
}

CMAJ 2011. DOI:10.1503/cmaj.101740 